\title{
QUESTIONNAIRE SURVEY ON A BEHAVIOR OF BUSINESSES, ETC. AROUND SHINJUKU STATION DURING THE GREAT EAST JAPAN EARTHQUAKE
}

\author{
Jun SHINDO ${ }^{1)}$, Tatsuya HIRAMOTO ${ }^{2)}$, Masahiro MURAKAMI ${ }^{3)}$ and Yoshiaki HISADA ${ }^{4)}$ \\ 1) Sompo Japan Nipponkoa Risk Management Inc., Tokyo Japan, jun.shindo@sjnk-rm.co.jp \\ 2) Graduate School, Architecture Kogakuin University, Tokyo Japan, tatsuya_hiramoto@sc.kogakuin.ac.jp \\ 3) Member, School of Architecture, Department of Urban Design and Planning, Kogakuin University, Dr. Eng., \\ Tokyo Japan, murakami@cc.kogakuin.ac.jp \\ 4) Member, School of Architecture, Department of Urban Design and Planning, Kogakuin University, Dr. Eng., \\ Tokyo Japan, hisada@cc.kogakuin.ac.jp
}

\begin{abstract}
In this paper, according to the survey, it was able to grasp reality of high-rise building-specific damage that occurred at the Great East Japan Earthquake ("the 3.11 Earthquake"), initial response of regional businesses, and support to the people who were unable to return home. In addition, we clarified the future issues learned from the actual situation and proposed efforts to enhance disaster prevention in cooperation with the local communities to minimize the disruption of a large-scale earthquake.
\end{abstract}

Key Words: Businesses, Around Shinjuku Station, Initial Response, Collaboration with Local Communities, High-rise Building, DCP

\section{PREFACE}

In case of large-scale earthquake such as Tokyo Inland earthquakes, the cluster of high-rise buildings in the Shinjuku West Gate area with a huge day time population is expected to see a large number of injured people inside the buildings, arrest of functions including broken elevators and essential utility outage, and confusion caused by people unable to move or return home. Under such circumstances, as public support is limited, collaborative effort in local communities is required to address the problems and challenges that emerge shortly after a disaster, Since 2008, a full-scale collaboration among local communities and businesses around Shinjuku Station has started (Murakami, Hisada ${ }^{1}$, Shindo et al. ${ }^{2}$, Kojima $^{3)}$ etc.).

At the occurrence of The Great East Japan Earthquake on March 11 th 2011 at 2.46pm, public transport in Tokyo Metropolitan area was paralyzed and many people had difficulty returning home. In Shinjuku, where an earthquake of intensity 5 lower was observed, not only communication function went down with both landlines and mobile lines flooded but also a large number of people who were 
stranded by shutdown of the major railway lines poured into the public facilities and the evacuation centers in the Shinjuku ward. In these circumstances, it is estimated that the high-rise buildings in the West Shinjuku area suffered various damages and the building management companies as well as the tenant businesses implemented assistance activities. However, not many survey researches have been published on what activities actually took place.
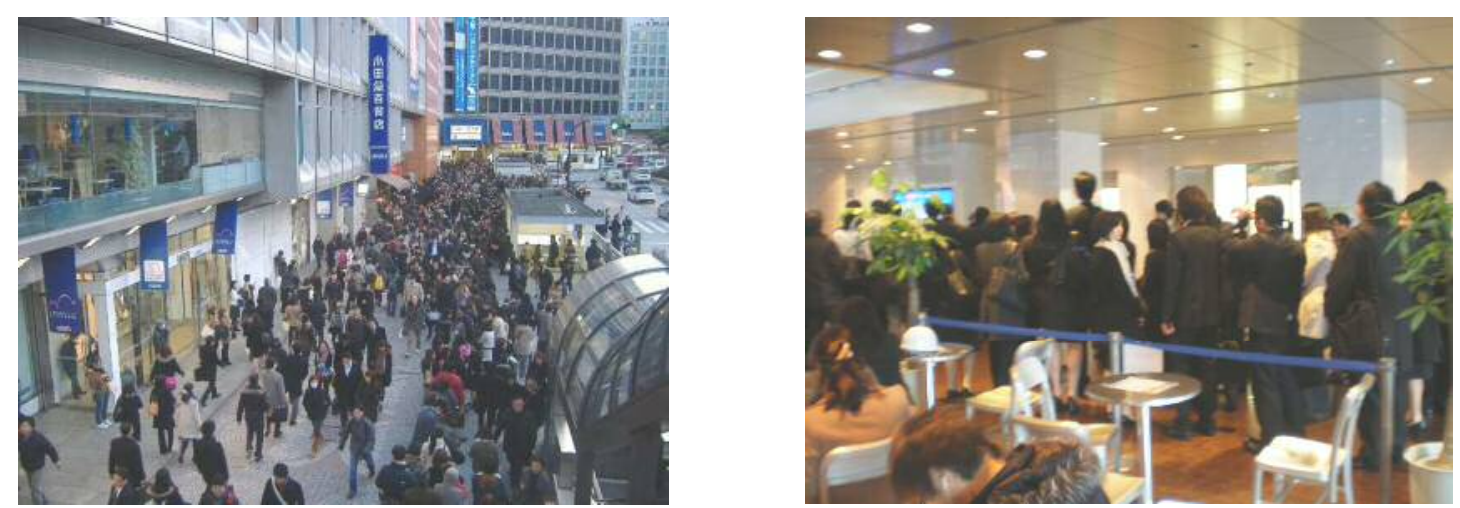

Photo 1 The West Gate of Shinjuku Station at the time of the Great East Japan Earthquake (Left: around Shinjuku Station, Right: a lobby on the ground floor of a building near the station)

A questionnaire survey on damages caused to the Metropolitan area by the Great East Japan Earthquake was conducted by Tokyo Fire Department ${ }^{4}$, targeting households and offices in the areas in charge. It investigated how furniture and fixtures fell and moved against how they had been fixed and in relation to building structure. How preventive measures had been taken was also questioned. The survey encouraged to implement preventive measures and described the importance. Midorikawa et al. ${ }^{5)}$ conducted a questionnaire survey targeting high-rise apartments in Chuo ward, which determined the extent of damage to rooms by apartment floor, and discussed future counter measures for long-period ground motion. Another research was conducted by Hida, Nagano ${ }^{6}$ with a questionnaire for the residents of high-rise RC apartments of more than 24 stories with strong motion observation in place in Kanto and Kansai regions. Their research studied mental state of the residents and the scope of damage inside the buildings.

With the above mentioned researches in mind, this paper focused on damage situation and initial response of management companies and tenants of high-rise buildings mainly used for business purposes. More precisely, based on a questionnaire survey by the Disaster Prevention Countermeasure Conference for Shinjuku Station Areas West Gate Division (hereinafter called "West Gate Division"), for which the authors serve as the secretariat, targeting the business members operating in the Shinjuku West Gate area (hereinafter called "the questionnaire"), this paper comprehends the damage situation and the initial response during the 3.11 Earthquake and examines problems and challenges that may be faced when an inland earthquake hits Tokyo. Also, it clarifies the problems of community collaboration in regional disaster prevention and delineates a direction of the countermeasures.

\section{THE OUTLINE OF THE QUESTIONNAIRE SURVEY ON BEHAVIOR OF BUSINESSES IN THE GREAT EAST JAPAN EARTHQUAKE}

\subsection{Respondents and collection of the questionnaire}

The questionnaire survey consists of two questionnaires; one for the companies which manage and 
understand the entire situation of the buildings (hereinafter called "management company/-ies") and the other one for the tenants of the buildings. The management companies were asked to distribute the tenant questionnaire to some of their own tenants. The survey started on April 10, 2011 for the management companies in charge of 22 buildings.

16 management companies and 23 tenants responded to the questionnaire. The respondents were free to choose from 2 kind of the questionnaires mentioned above, so that some businesses like a hotel, which were the only tenant of their building, chose the questionnaire for the tenants, not the one for the management companies.

\subsection{Contents of questionnaire}

The questions for both the management companies and the tenants respectively were designed as is shown in the following chart. See the appendix for the details of the questions.

Table 1 Questions for management companies

1.Building outline 2.Damages occurred in the building on the day of the 3.11 Earthquake 3.Disaster control headquarters 4.Actions taken on the occurrence of the 3.11 Earthquake 5.Implement status of behaviors and actions in the disaster defense plan 6.evacuation from the building 7.Provision of information to remaining people in and around the building 8.Acceptance of stranded commuters 9.Overnight stay in common areas 10. Past seismic countermeasures 11.Future effort 12.Comments and others

Table 2 Questions for tenants

1.Company outline 2. Damages occurred in the office 3.Safety confirmation of employees 4 . Evacuation of employees 5. Decision of returning home 6. Overnight stay in the office 7. Past seismic countermeasures 8 . Implement status of behaviors and actions taken in the context of disaster defense plan 9. Disaster control headquarters 10.Information collection activity 11. Provision of information to employees 12. Problems and reflection points 13.future effort 14.Others

\subsection{Seismic intensity of the high-rise buildings in the Shinjuku West Gate area where the respondents of the questionnaire reside}

Kubo et al. ${ }^{7)}$ reported the quake in the high-rise buildings in the Shinjuku West Gate area was observed in the Kogakuin University's Shinjuku campus building, standing approximately 143 meters, with 29 stories above the ground and 6 underground stories. According to the report, intensity 4 on the $6^{\text {th }}$ floor, 5 lower on the ground floor, 5 upper on the 22th and 6 lower on the $29^{\text {th }}$ floor were respectively observed. It is necessary to keep in mind that the questionnaires in this paper are intended for the high-rise buildings and the tenants, which could differentiate the seismic intensity by floors.

\section{RESULTS OF THE QUESTIONNAIRE}

As described previously, the questionnaire had two separate questionnaire sheets; one for the building management companies and the other one for the tenants. The results therefore are also reported in two different parts.

\subsection{Building management company}


(1) Outline of the responding management companies

16 management companies responded to the questionnaire manage 16 buildings which are all high-rise buildings of more than 90 meters high, with a total floor space of $40,000 \mathrm{~m}^{2}$. They were built in the period between 1974 and 2008. The occupancy rate varied from building to building. 12 of them were multi-tenant buildings having more than 10 tenants. Through mostly used as office, some were used for restaurants, medical clinics, rental meeting rooms or lecture rooms. 6 buildings had a vibration control mechanism, 5 of which were built in 1990s or later and one in 1970s. (Table3, Fig.1, Fig.2)

Table 3 Outline of responding buildings

\begin{tabular}{c|r|c|c|c|c|c|c|c|c}
\hline $\begin{array}{c}\text { Building } \\
\text { name }\end{array}$ & Built in & $\begin{array}{c}\text { above } \\
\text { the } \\
\text { ground }\end{array}$ & $\begin{array}{c}\text { No. of } \\
\text { tenants }\end{array}$ & $\begin{array}{c}\text { vibration } \\
\text { control } \\
\text { mechanism }\end{array}$ & $\begin{array}{c}\text { Building } \\
\text { name }\end{array}$ & Built in & $\begin{array}{c}\text { above } \\
\text { the } \\
\text { ground }\end{array}$ & $\begin{array}{c}\text { No. of } \\
\text { tenants }\end{array}$ & $\begin{array}{c}\text { vibration } \\
\text { control } \\
\text { mechanism }\end{array}$ \\
\hline \hline A & $90 \mathrm{~s}$ & $20+$ & $\begin{array}{c}\text { More } \\
\text { than } 200\end{array}$ & $\begin{array}{c}\text { No } \\
\text { response }\end{array}$ & I & $2000 \mathrm{~s}$ & $20+$ & $10 \sim 100$ & Yes \\
\hline $\mathrm{B}$ & $80 \mathrm{~s}$ & $20+$ & $10 \sim 100$ & No & $\mathrm{J}$ & $2000 \mathrm{~s}$ & $20+$ & $10 \sim 100$ & Yes \\
\hline $\mathrm{D}$ & $70 \mathrm{~s}$ & $20+$ & $10 \sim 100$ & No & $\mathrm{K}$ & $70 \mathrm{~s}$ & $20+$ & $\begin{array}{c}\text { less } \\
\text { than10 }\end{array}$ & No \\
\hline $\mathrm{E}$ & $90 \mathrm{~s}$ & $20+$ & $10 \sim 100$ & Yes & $\mathrm{L}$ & $80 \mathrm{~s}$ & $20+$ & $\begin{array}{c}\text { less } \\
\text { than } 10\end{array}$ & No \\
\hline $\mathrm{F}$ & $90 \mathrm{~s}$ & $20+$ & $10 \sim 100$ & No & $\mathrm{M}$ & $80 \mathrm{~s}$ & $20+$ & $10 \sim 100$ & $\begin{array}{c}\text { No } \\
\text { rsponse }\end{array}$ \\
\hline $\mathrm{G}$ & $90 \mathrm{~s}$ & $20+$ & $10 \sim 100$ & Yes & $\mathrm{N}$ & $80 \mathrm{~s}$ & $20+$ & $10 \sim 100$ & No \\
\hline $\mathrm{H}$ & $2000 \mathrm{~s}$ & $20-$ & $10 \sim 100$ & Yes & $\mathrm{P}$ & $80 \mathrm{~s}$ & $20+$ & $\begin{array}{c}\text { less } \\
\text { than } 10\end{array}$ & No \\
\hline
\end{tabular}

*)"20+": in and higher than $20^{\text {th }}$ floor "20-": lower than $20^{\text {th }}$ floor

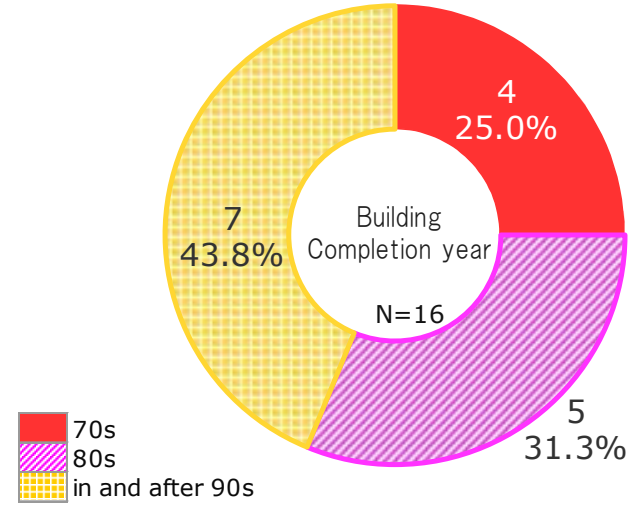

Fig.1 Building completion year

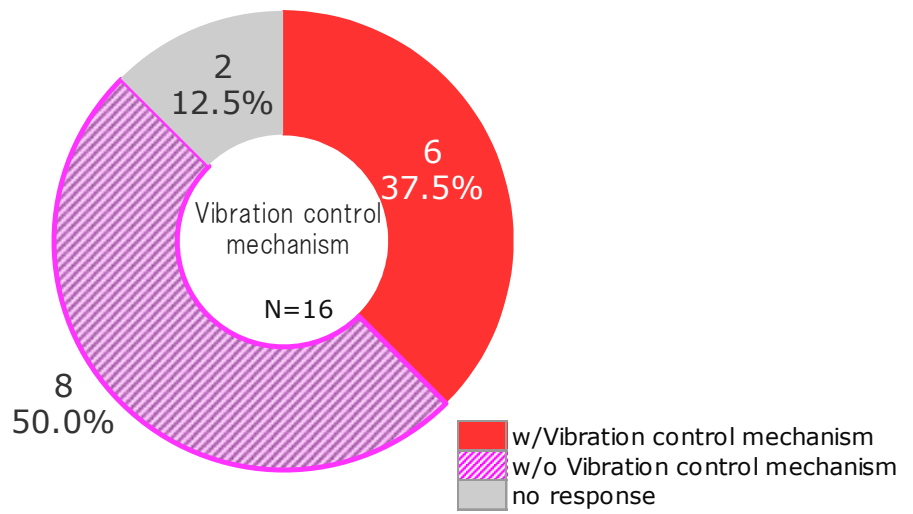

Fig.2 Vibration control mechanism

\section{(2) Damages occurred in the building on the day of the 3.11 Earthquake}

Damages occurred in the buildings on that day were investigated in the categories of "infrastructure", "outside the building" and "inside the building". For "infrastructure", the most common trouble found was with "incoming calls" with 12 reported cases (Fig.3), followed by "other communication means" with 7 reported cases. Damage to "mobile communication" was the biggest in the category of "other communication means" according to answers given to the open-ended question. Troubles with incoming calls were mostly caused by congestion. Damages to "electricity, gas and water supply" were caused by water leaked from sprinklers by flange misalignment or released fire door. It can be said that 
no serious infrastructural damage occurred in the high-rise buildings of the Shinjuku West area. Some offices reported that automatic gas shutoff valves did not work in the Great East Japan Earthquake. Some buildings manually operated the valves, while others didn't. It is necessary to consider the possibility of earthquake fire; Earthquake motion where long-period components are superior may not activate automatic shutoff valves when it doesn't reach a preset velocity.

For the external parts of each building, no major damage was reported except one case that a part of the exterior wall fell off (Fig.4).

For inside a building, part of the ceiling collapsed (13 reported), and interior wall fell off ( 9 reported cases). 6 reported that the fire-retarding doors didn't close properly (Fig.5).

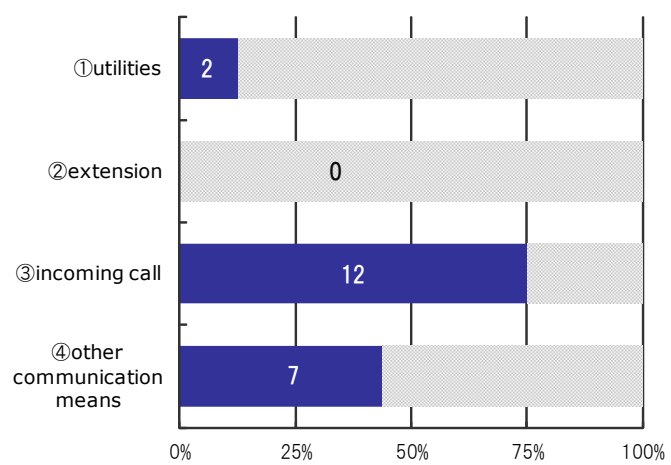

Fig.3 Infrastructural damage

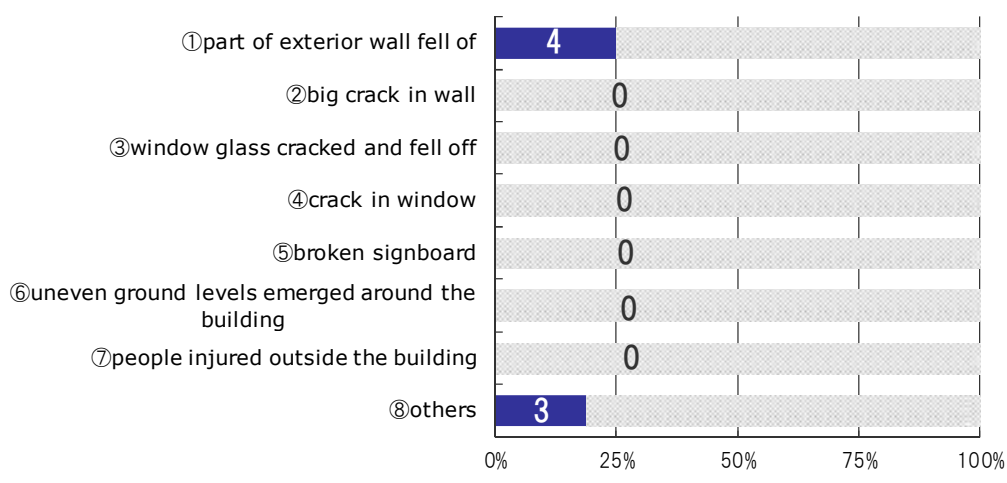

Fig.4 External damage

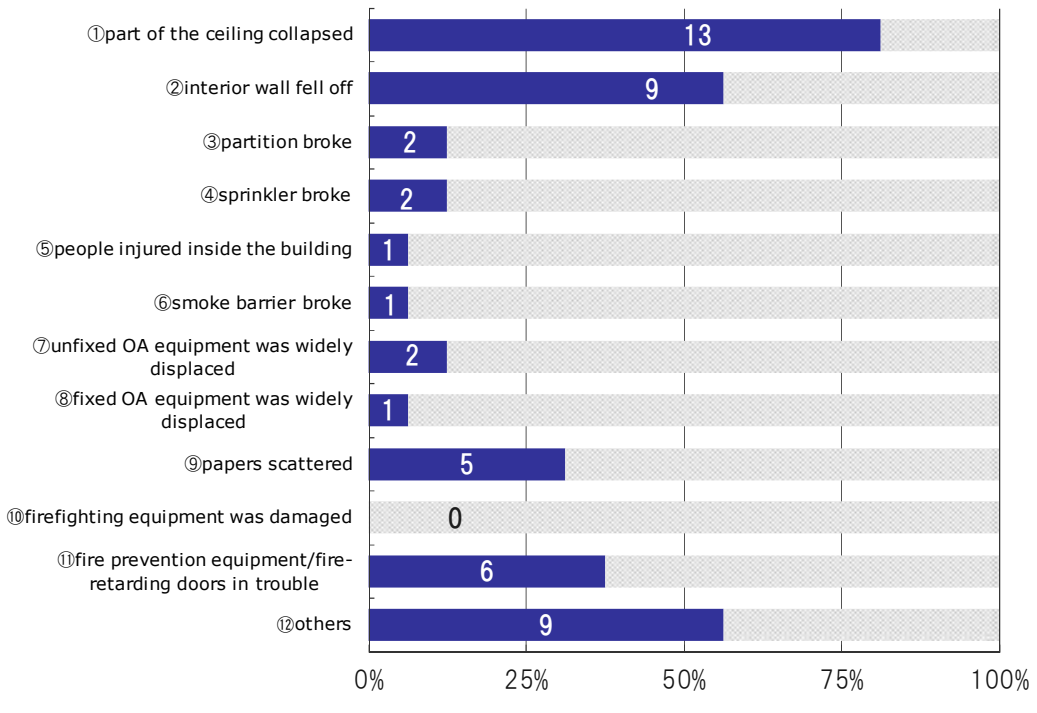

Fig.5 Internal damage 
As for the items with more than two reported cases of internal damage, buildings with and without a vibration control mechanism are compared as shown in Fig.6. The buildings with a vibration control mechanism were found less damaged than the one without it in the items other than "sprinkler was broken", "unfixed shelves or office automation equipment widely moved" and "fire prevention equipment/fire-retarding doors in trouble". The items of damage which the buildings with a vibration mechanism require further sufficient examination.

(1) part of ceiling collapsed

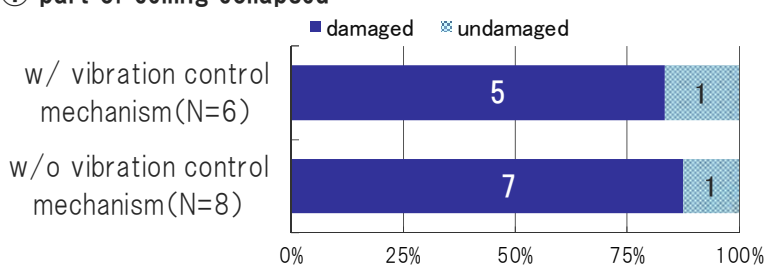

(3) partition fell down

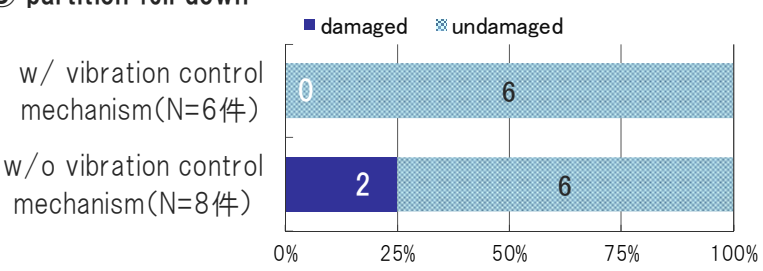

(7) unfixed $O A$ equipment widely displaced

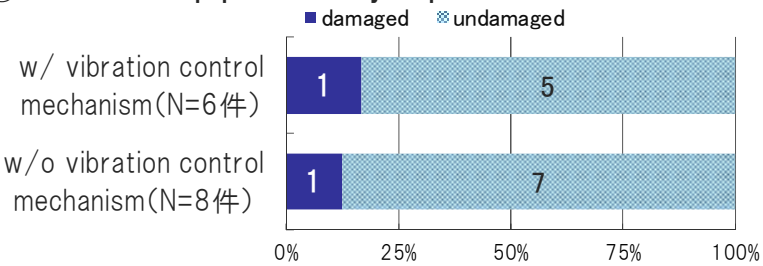

(11) fire prevention equipment/fire-retarding doors in trouble

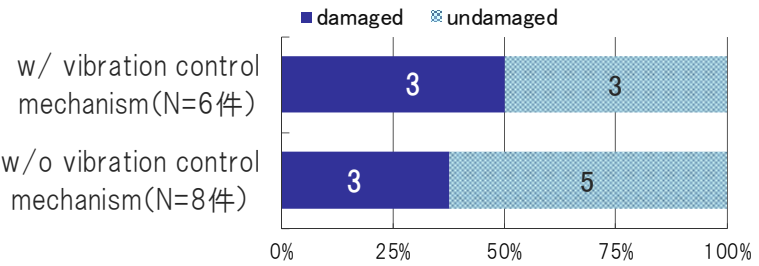

(2) interior wall fell off

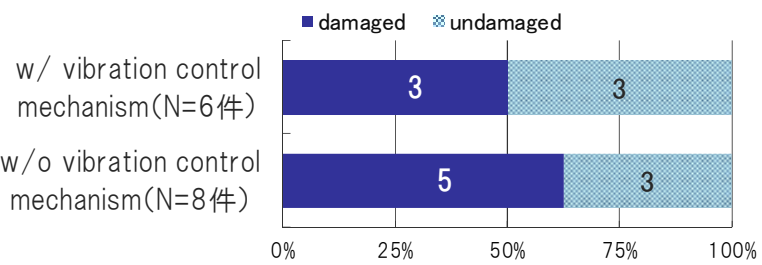

(4) sprinkler broke

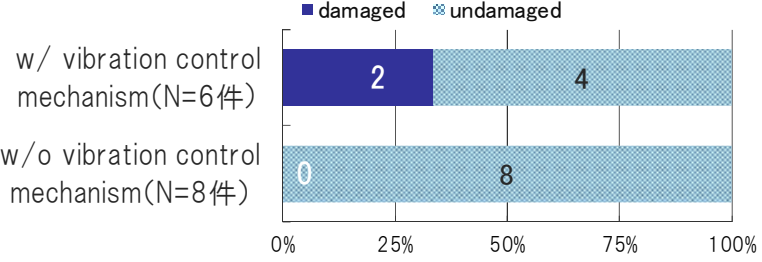

(9) papers scattered

W/ vibration control mechanism( $\mathrm{N}=6$ 件)

w/o vibration contro mechanism ( $\mathrm{N}=8$ 件)

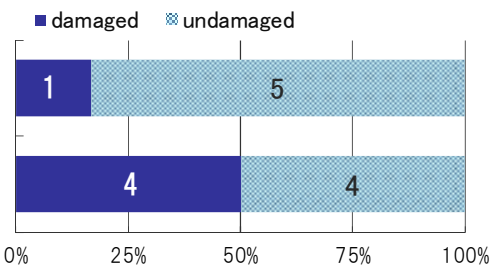

Fig.6 Comparison of damage in the buildings with and without a vibration control

For the elevators inside the building, the most common damage was "entangled control wires or lopes" with 4 reported cases, followed by "loss of inner parts" with 2 cases and "dislocated door" with one reported case. The elevators were stopped under control soon after the 3.11 Earthquake. 4 office buildings had to wait at least one month to have the elevators recovered. Vertical movement of people in high-rise buildings is dependent on the elevators, and the result above exposed the vulnerability of tall buildings to earthquakes (Fig.7).

9 buildings completed their check on the damage on the day of the 3.11 Earthquake. 3 buildings completed on the following day and one after March 13. 3 buildings did not respond. 


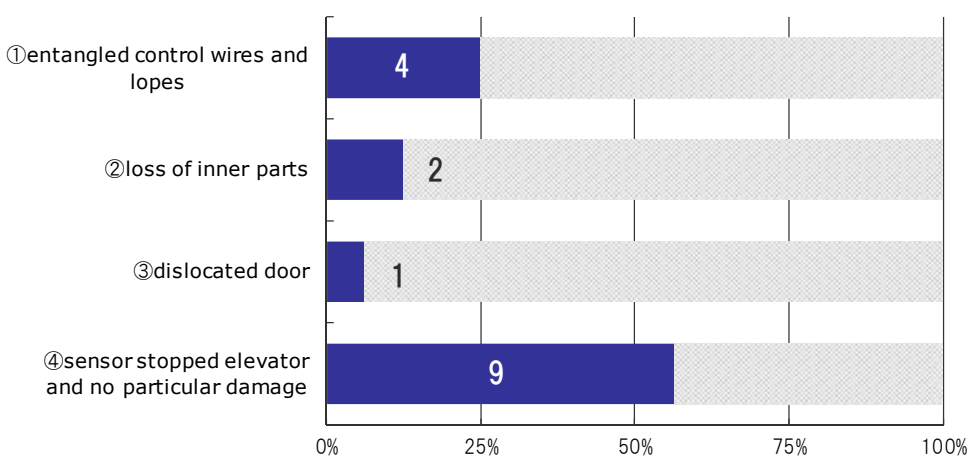

Fig.7 Damage in elevator

As for the elevator related damage items, the buildings with and without a vibration control mechanism were compared as shown in Fig.8.

Fewer troubles were reported by the buildings with a vibration control mechanism. However, according to some existing studies such as Architectural institute of Japan ${ }^{8)}$, it had been indicated that the percentage of damage to elevator was not only determined by the building structure but also by what year of the guide for design and construction of elevator was adopted $(1972,1981,1998,2009)$. The older the guide was, the higher the damage rate was generated.

(1)entangled control wires and lopes
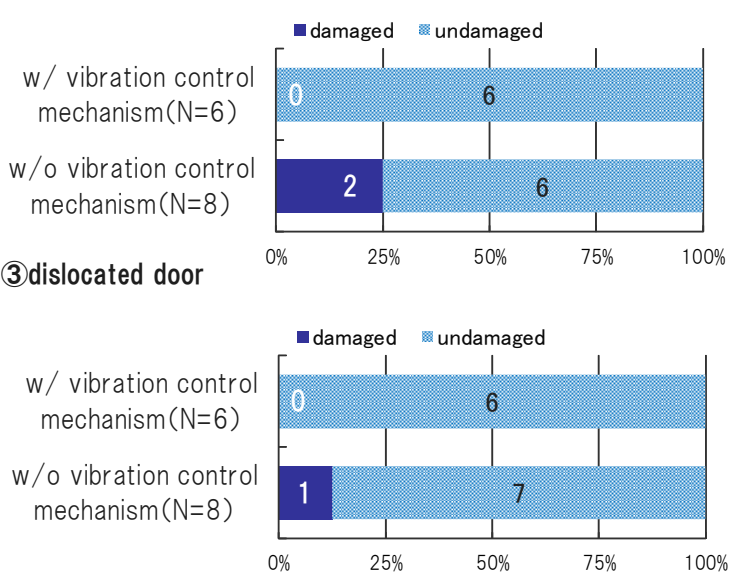

(2)loss of inner parts

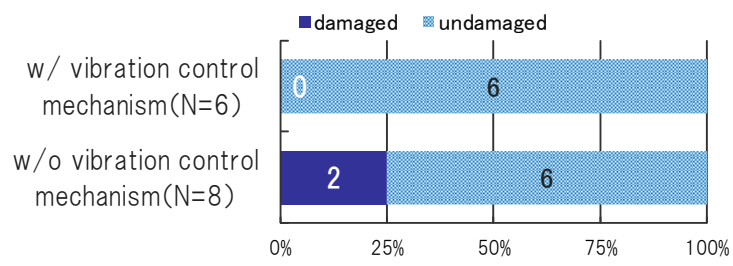

Fig.8 Comparison of damage in elevators with and without vibration control

\section{(3) Disaster control/crisis management headquarters}

Of the responding buildings, 11 (69\%) formed their own disaster control headquarters. All of them responded that the headquarters were formed "immediately after the 3.11 Earthquake" within their respective disaster control centers. The activities included collection of information on damage situation both inside and outside of the building, announcement using an emergency broadcasting equipment and provision of assistance to stranded people. Of those which did not open a headquarters, 4 buildings described that "an earthquake of intensity 6 or more was conditioned by their rules to form a headquarters" and "no major damage was found" as the reasons for not formatting a headquarters (Fig.9).

If a disaster, such as a large-scale earthquake, occurs, certain activities including information gathering and internal announcements for the tenants would take place through a disaster control headquarters located in each building's disaster control center, although a variation in handling was 
observed during the Great East Japan Earthquake.

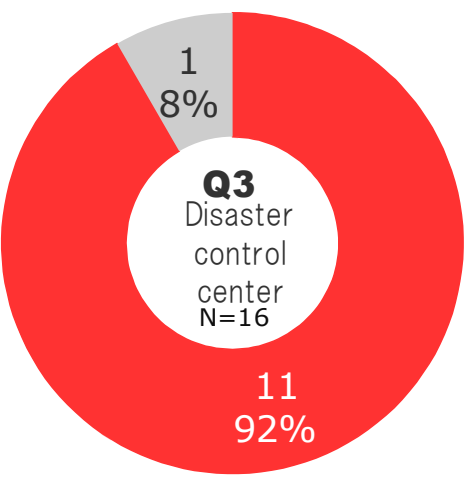

Headquarters was formed for the 3.11 Earthquake Headquarters was not formed No response

Fig.9 Disaster control center

(4)Provision of information by management companies on the occurrence of the 3.11 Earthquake In the Shinjuku Station West area, where electric supply was not impacted by the Great East Japan Earthquake, people gathered information through the Internet and TV (Fig.10). Some said that they directly contacted a local administrative office or transportation facilities to get area-specific information.

In addition, the questionnaire asked the time required for the confirmation of the injured in the building. Among 11 buildings responded, one said approximately half an hour, 6 said less than two hours and 4 said more than two hours.

An accurate, smooth information gathering is important in giving directions and information via internal announcements through which building management companies asked the building users to behave in an orderly manner. Assuming that a large-scale earthquake occurs directly beneath the Tokyo Metropolitan area, information gathering equipment that can be used even under power outage is needed to address the situation in a similar way in the Great East Japan Earthquake. In addition, some systems are needed to share area information that is currently obtainable only through a direct contact with a local administrative office and transport facilities.

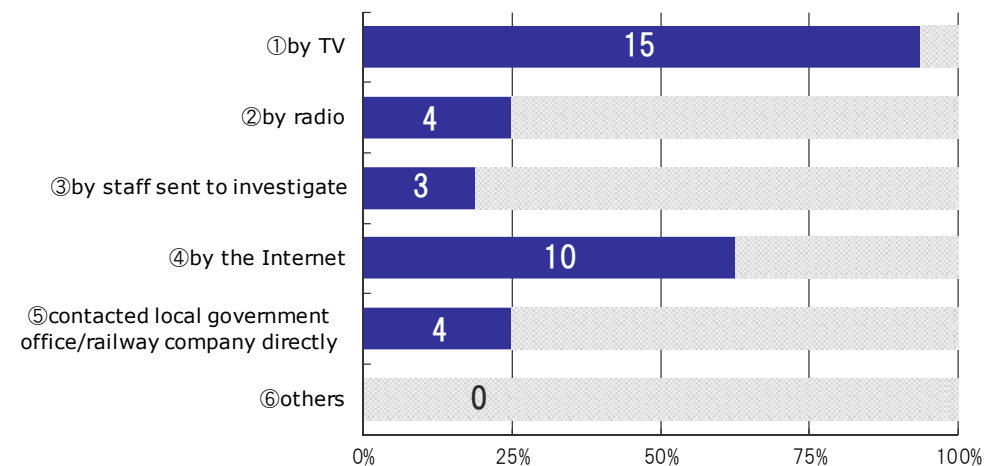

Fig.10 Provision of information on the day of the 3.11 Earthquake

\section{(5) Behaviors and actions in the disaster defense plan}

It is fundamental to comply with a disaster defense plan in the initial responses on the occurrence of an earthquake. In the questionnaire, 14 management companies responded that they could implement the actions set in their disaster defense plan including the formation of headquarters, collection and provision of information and making announcements (Fig.11). The management companies which could not take such actions as planned described that the reasons are "the emergency telephone system 
was not used for communicating information", "incoming call were disconnected and they could not contact the tenant companies".

Regarding actions set in a disaster defense plan, a smooth evacuation is important in the case of fire. However, assuming an earthquake occurring directly beneath Tokyo, it is important to promptly grasp the situation while ensuring smooth communication and information flows in a building so that the building management company to encourage the tenants to behave in an orderly manner.

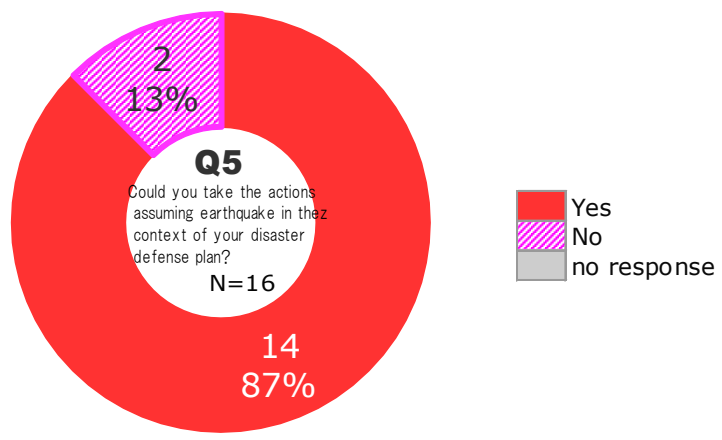

Fig.11 Actions in disaster defense plan

(6) Provision of information to remaining people in and around the building

The questionnaire asked how information was provided to the people remaining in and around the building. "Through announcements (in the building)" ranked top with 9 reported cases, followed by "communication by security guards" with 6 cases and "notice on the walls" with 5 cases. 5 management companies did not particularly provide information (Fig.12).

In an open-ended question, the contents of announcements made on the day were questioned. In general, information regarding "earthquake", "building facility", "safety" and "support for stranded commuters" were provided. The details are given in Table 4.

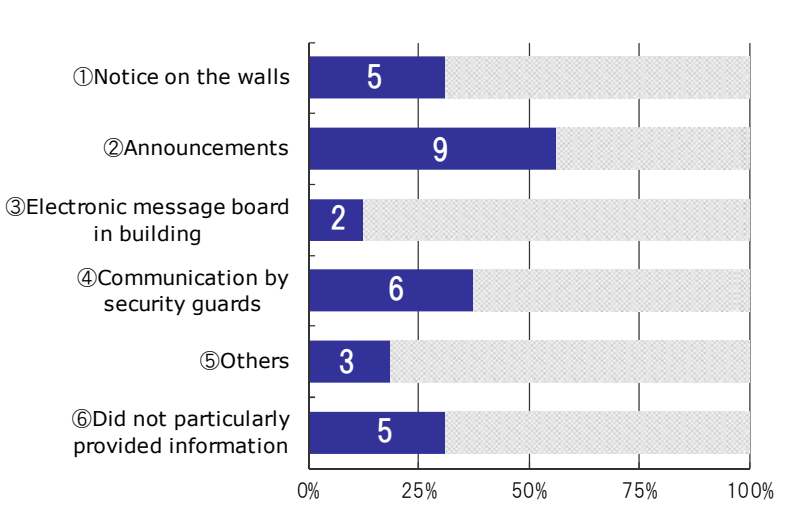

Table 4 Contents of announcements

\begin{tabular}{|l|l|}
\hline Announcement about... & Descriptions \\
\hline \multirow{4}{*}{ Earthquake } & An earthquake occurred \\
\cline { 2 - 2 } & Warning for aftershock \\
\cline { 2 - 2 } & Damage situation in the building \\
\hline Building and facilities & Gas supply stopped \\
\cline { 2 - 2 } & Air conditioning equipment being checked \\
\cline { 2 - 2 } & Elevators stopped \\
\hline \multirow{3}{*}{$\begin{array}{l}\text { Safety } \\
\text { commutling of Stranded }\end{array}$} & Safety of individuals \\
\cline { 2 - 2 } & Ihe building is safe \\
\cline { 2 - 2 } & $\begin{array}{l}\text { Information on establishment of emergency center } \\
\text { building }\end{array}$ \\
\hline & Overnight stay in the building \\
\cline { 2 - 2 } & Information on supply of stockpiled \\
\hline
\end{tabular}

Fig.12 Means of information provision

\section{(7) Acceptance of stranded commuters}

In the Great East Japan Earthquake, many commuters around the Shinjuku West Gate area were unable to go home. Among the responding management companies, 6 accepted such people to their buildings and 2 of them provided material assistance (Fig.13).

In order to prevent potential confusion in the local area by the occurrence of numerous stranded people, in addition to protecting the employees staying in the buildings, the cooperation with the local buildings is required to temporarily accept "unorganized stranded people" who are for example in the area for shopping. A following research found that 5 respondents which did not accept any people to their buildings had actually been ready to accept a limited number of people referred by a local authority. Some of them however did not do so because they could not have reached a local authority. This 
reaffirmed the need of informative communication along with a smooth referral.

Additionally, 8 management companies answered "some people stayed overnight in their common areas" to the question if there was anyone who stayed there overnight regardless of whether the building systematically accepted stranded people or not.

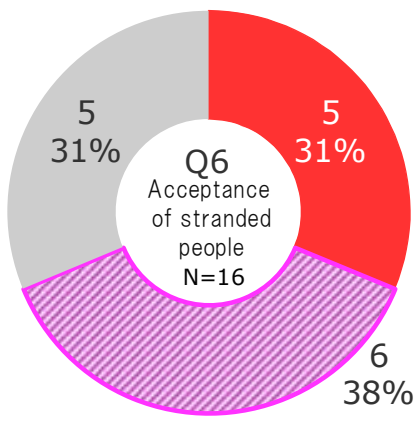

Yes

No

no response
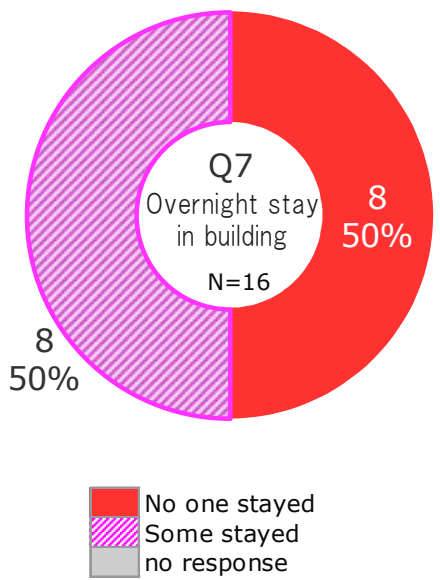

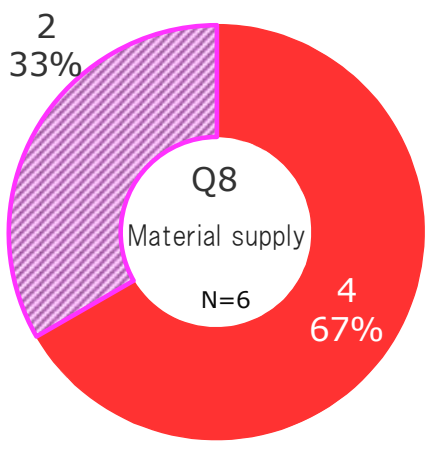

No

Yes

no response

Fig.13 Acceptance of stranded people, material assistance and overnight stay in building

(8)Earthquake countermeasures before the occurrence of the Great East Japan Earthquake, and problems and reflection points in the initial responses taken during the 3.11 Earthquake

The questionnaire asked about the efforts of earthquake countermeasures taken before the 3.11 Earthquake in an open-ended question. The answers returned included "bi-annual disaster drills", "manuals or contingency plans", "stock of food and emergency supplies" and "furniture fall prevention".

Problems and reflection points regarding the initial responses taken during the 3.11 Earthquake are shown in the next table. The building management companies, despite their basic disaster preparation, found problems and reflection points, such as "stock shortage in terms of variety and volume", "insufficient information gathering" and "contents of in-building announcements". Regarding countermeasures necessary in the event of an earthquake, it is important that concerned parties share a clear image of what would happen through disaster drills based on an anticipation of damage, for example. Periodic reviews of current preparation are needed as well.

Table 5 Problems and reflection points for the building management companies regarding their handling during the 3.11 Earthquake

\footnotetext{
(1) Support for visitors

- Materials and equipment to support visitors were not enough

(2) Acceptance of stranded commuters

- It was difficult to accept/support stranded commuters along with addressing people in the building

- No stock of food and blankets to provide

- No stock of food and blanket as the building was not meant for a temporarily shelter

- Not enough bath rooms

(3) Collection and provision of information

- A dedicated person to collect area information should have been appointed

- Ways to provide information to visitors need a review

(4) In-building communication and announcements

- Communication with the tenants was not smooth as telephone lines were congested

- People in the building should be more informed of the extension numbers to avoid using mobile phones

- The building did not make an announcement that the building was safe. As a result, people inside rushed to the emergency

staircase, which prevented the management company from reaching the site quickly.
} 
- A system is important to make an announcement immediately after an earthquake occurred

(5) Disaster drills

- With a partial review of disaster defense plan, disaster drills should be implemented to encourage people to be able to take more practical actions.

(6) Long-period ground motion

- Preparation for long-period ground motion is needed

\section{(9)Earthquake countermeasures after the Great East Japan Earthquake}

Based on the problems and the reflection points discovered in the Earthquake, an open-ended question was asked regarding the future earthquake countermeasures which the respondents considered. The answers included disaster drills focusing on earthquakes, review of the defense plans, the manuals and the evacuation plans.

Building management companies which manage a fire prevention property with a certain amount of total floor area are obliged by Japanese Fire Service Amendment Bill 2009 to include large-scale earthquakes in the disaster defense plan. The training text books for the staffs at a disaster control center of a building management company ${ }^{11)}$ explain self-defensive fire-fighting operations at the time of an earthquake. However, as for disaster drills, they show only the guidelines for how to handle a fire emergency. It is therefore expected that the focus of regular drills at companies is placed on evacuation drills. Earthquake drills particularly assuming a strong local earthquake are ideally conducted based on the characteristics of the buildings and the community. Concerned parties will need to collaborate to review the concept of earthquake countermeasures to be taken in the community and design and implement their earthquake drills.

\subsection{Tenant}

\section{(1)Responding tenants}

23 tenants responded to the questionnaire; 19 of which used the buildings as office. 3 tenants used them as accommodation and one as clinic. 14 of the 19 office tenants had their own headquarters, 4 tenants on a low level floor (GF to $\left.9^{\text {th }}\right), 6$ tenants on a mid-level floor $\left(10^{\text {th }}\right.$ to $\left.19^{\text {th }}\right)$ and 13 on a high-level floor $\left(<20^{\text {th }}\right)$. For the multi-floor users, their highest floors were counted.

Table 6 Responding tenants and their use of building

\begin{tabular}{|c|c|c|c|c|c|c|c|c|}
\hline $\begin{array}{l}\text { Company } \\
\text { name }\end{array}$ & floor & use & $\begin{array}{c}\text { Company } \\
\text { name }\end{array}$ & floor & use & $\begin{array}{c}\text { Company } \\
\text { name }\end{array}$ & floor & use \\
\hline A & upper floors & office & 1 & middle floors & office & $Q$ & lower floors & office \\
\hline$B$ & upper floors & office & J & upper floors & office & $\mathrm{R}$ & upper floors & office \\
\hline C & upper floors & office & K & lower floors & clinic & $S$ & upper floors & office \\
\hline D & middle floors & office & L & lower floors & office & $\mathrm{T}$ & upper floors & office \\
\hline$E$ & middle floors & office & M & upper floors & office & U & upper floors & office \\
\hline $\mathrm{F}$ & middle floors & office & $\mathrm{N}$ & upper floors & office & W & middle floors & office \\
\hline G & lower floors & office & 0 & upper floors & accommodation & $x$ & upper floors & accommodation \\
\hline $\mathrm{H}$ & middle floors & office & $\mathrm{P}$ & upper floors & accommodation & & & \\
\hline
\end{tabular}

\section{(2)Damage found in the tenants' office space}

Damage found in the office of the tenants was investigated in the two separate categories of "infrastructure" and "inside the office". For "infrastructure", the most common trouble found was "other communication means" with 10 reported cases, followed by "incoming call" with 7 reported cases (Fig.14). "Mobile phone" and "the Internet" were mentioned as "other communication means".

For inside the office, troubles of flaked interior wall were reported by 7 tenants. 6 reported part of the ceiling collapsed, and 4 said their unfixed office automation equipment moved. As well as the building management companies mentioned, damages were found mostly in non-structural components 
(Fig.15). For "others", some reported their servers and TVs overturned.

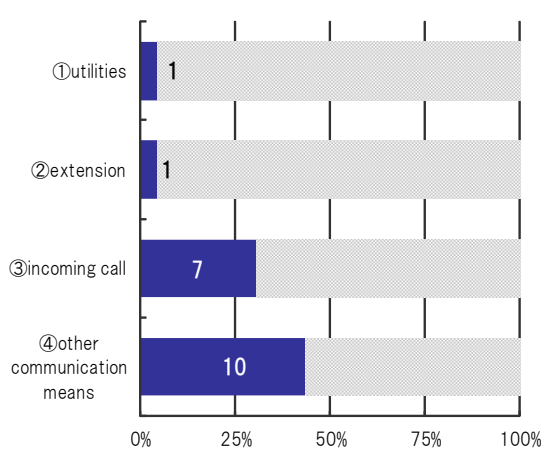

Fig.14 infrastructural damage

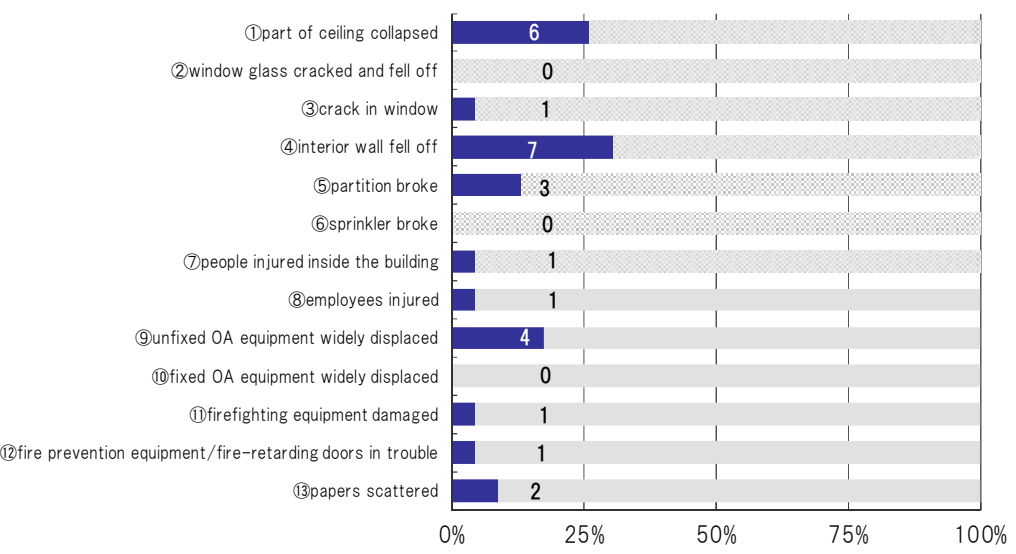

Fig.15 Damage in the office
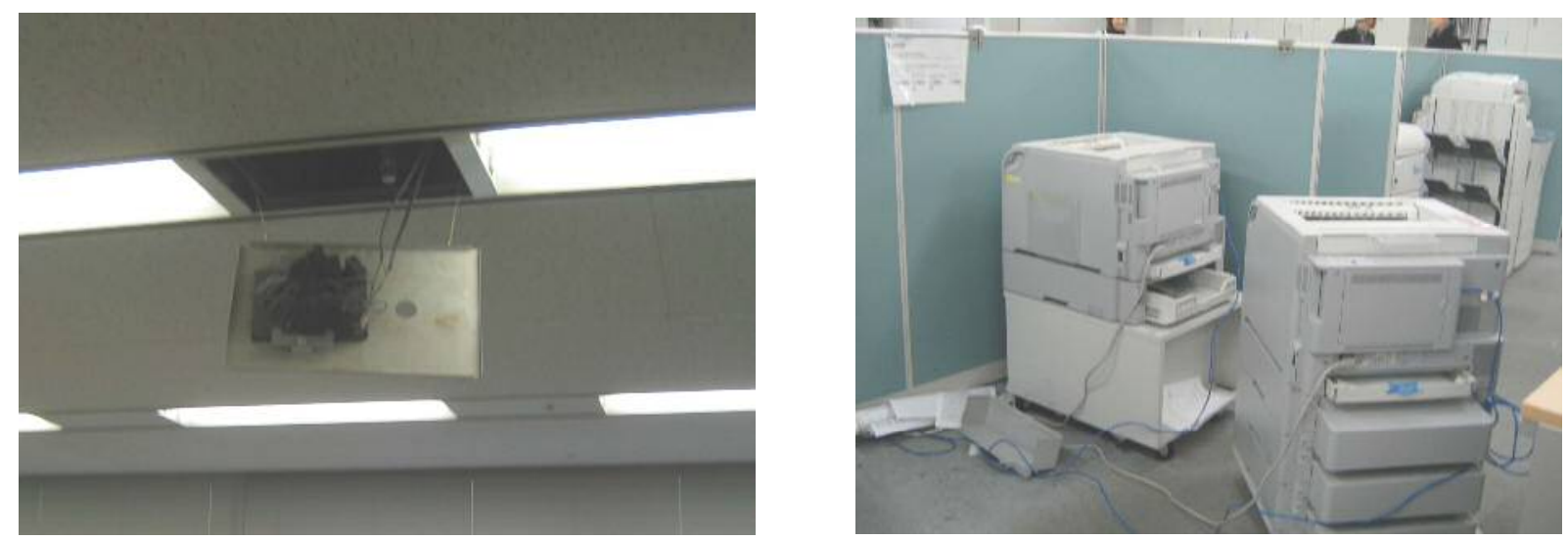

Photo 2 Damages in a local building ( $27^{\text {th }}$ floor) (left : part of the ceiling fell/right : displaced OA equipment)

\section{(3) Safety confirmation of employees}

21 tenants answered that they confirmed the safety of the employees, which is the basis for the initial responses to be taken in an office during an earthquake. The timing and the method were also asked in an open-ended question. 9 of 21 tenants confirmed the safety of the employees immediately after the 3.11 Earthquake. 10 tenants answered that they used "a safety confirmation method of the company" and 7 said "by telephone". The questionnaire asked the scope of the target of the employee confirmation. 10 answered "only the employees" and 11 said "both the employees and the family members" (Fig.16).
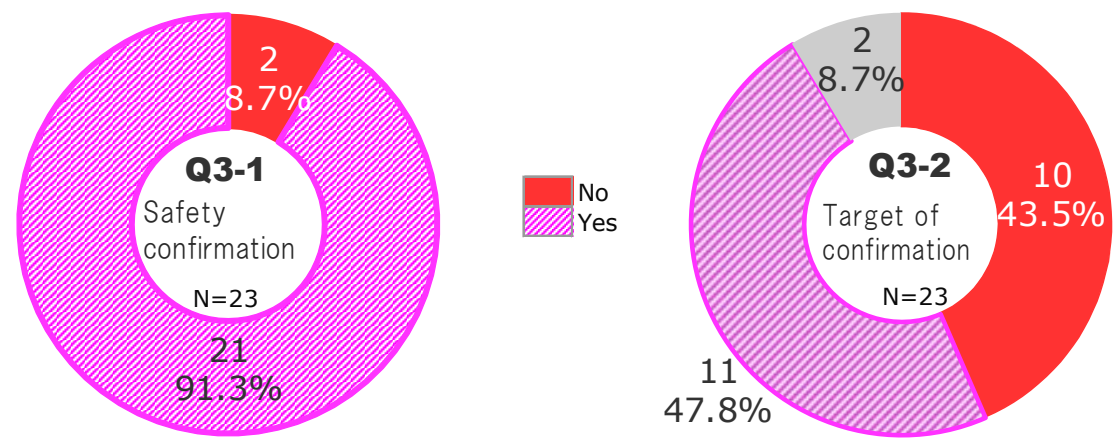

Employees only Employees and the family members No response

Fig.16 Safety confirmation and the target 


\section{(4) Evacuation of employees}

15 tenants ordered the employees to evacuate at the occurrence of the 3.11 Earthquake (Fig.17, left). The reasons why they ordered them to evacuate were asked in an open-ended question, and the answers included "risk of collapse" and "a prescribed temporary evacuation site". The reasons given by those which did not issue an evacuation directive included "the area was a non-evacuation area".

The same question was asked to the building management companies to find that no building ordered an evacuation (Fig.17, right). The reason included "no factor was observed such as fire that required an evacuation", "the building had anti-seismic reinforcement works" and "safety was secured by a building system". In summary, they did not order them to evacuate since the safety of the buildings had been secured

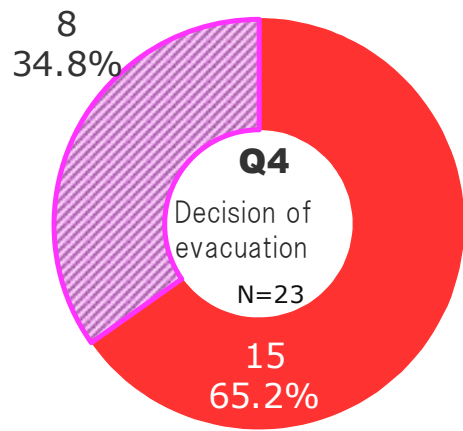

$<$ Tenant companies $>$
No directive issued Directive issued

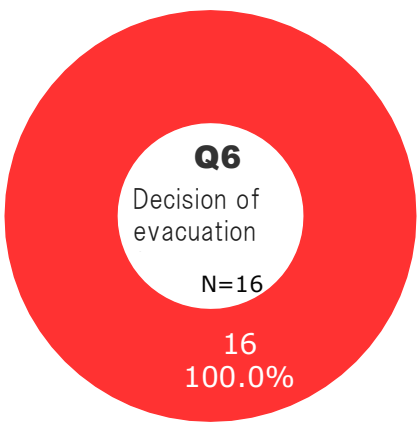

$<$ Building management companies $>$
No directive issued Directive issued

Fig.17 Decision of evacuation of employees

\section{(5) Decision of returning home}

The questionnaire asked whether the tenants companies decided a policy for the employees to return home after the 3.11 Earthquake. 13 issued such a policy (Fig.18). The details were given in answers to an open-ended question including "advised to stay in the office in principle" and "not to go home alone but to form a group of people leaving for a similar direction". During the 3.11 Earthquake, people in the Metropolitan area were faced with a big challenge of walking back home. The estimated cause was that the businesses in the area had different policies of the employees' returning home. When a large-scale earthquake happens in the Metropolitan area in the future, it will be necessary for each business entity to make an orderly move as an organization by setting rules to prevent the staff from moving freely and to let them wait in the office in principle as Council for the Alleviation of Subterranean Urban Earthquake Commuter Distress ${ }^{9)}$ advises. Such rules, which should aim to avoid regional confusion, will need to enhance the viability through the community collaboration in organizing ideas based on the understanding of the community and by the establishment of a system that encourages local businesses to mutually support temporary stop-over of the people.

\section{(6) Overnight stay in the office}

22 tenants answered that some people stayed overnight in the office on the day of the Great East Japan Earthquake (Fig.19). Food and other supplies for the people were secured "through emergency stockpile items of food and blankets" and "at near-by convenience stores". In the future, it will be necessary to build a certain amount of stockpiles for people in anticipation of temporary stop-over. 


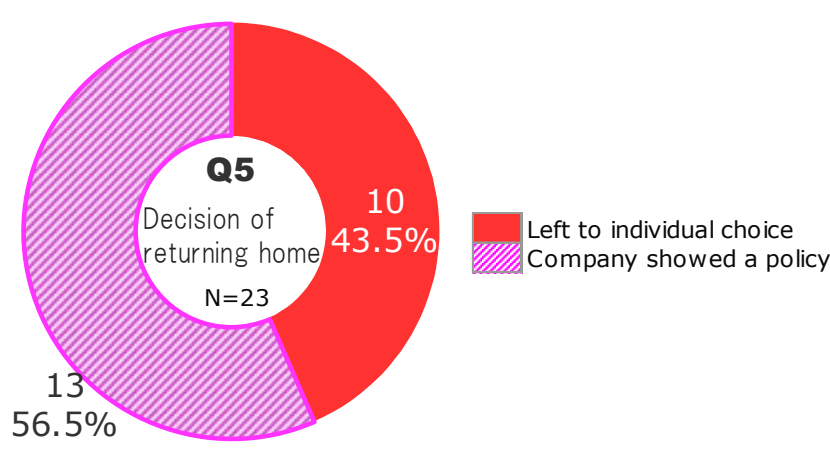

Fig.18 Decision of returning home

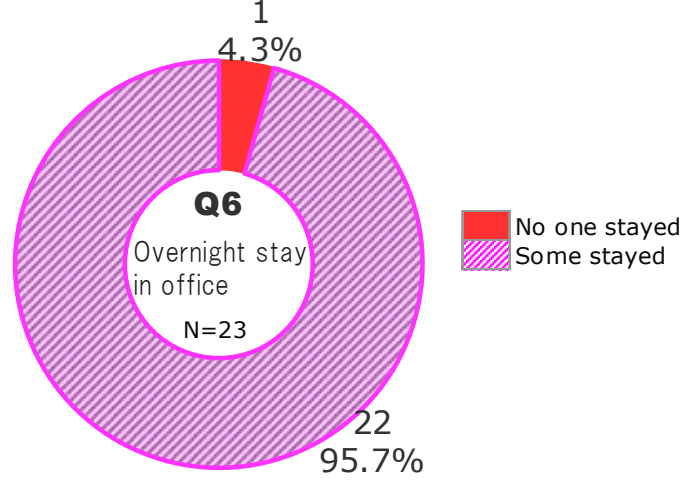

Fig.19 Overnight stay in the office

\section{(7) Behaviors and actions in the disaster defense plan}

While approximately 87 percent of the responding management companies answered that they could implement the actions set in their disaster defense plan, one-third of them answered they could not. The reasons included "timings of evacuation could not been decided" and "lack of understanding of the plan and roles" (Fig.20). It was presumable that the difference of handling in a fire and in an earthquake had not been well understood. In general, if a fire disaster occurs at a high-rise building, it is important for the people inside to promptly evacuate to a near and safe place because it is happening only in that building. In the case of an earthquake, however, they are to stay inside in the first place, unless there is a fire in the building. Generally speaking, prior to the 3.11 Earthquake, disaster drills had been carried out assuming a fire disaster but not an earthquake. This difference of idea for evacuation does not seem to have been adequately understood by offices. Each business will be required to pull together the ideas for evacuation, decision criteria in the case of a disaster in the tenant office and concrete actions to take.

\section{(8) Formation of disaster control/crisis management headquarters}

When the Great East Japan Earthquake occurred, more than a half of the responding businesses, that are 15 tenants, formed their own disaster control headquarters in the office. Activities performed there were given in response to the open-ended questions as follows; "communication and direction to the employees remaining in the office", "gathering information through TV and informing it to the remaining employees", "safety confirmation of the employees and the families", "understanding of damage and operation status of stores", "recovery activities of damaged stores" (Fig.21).
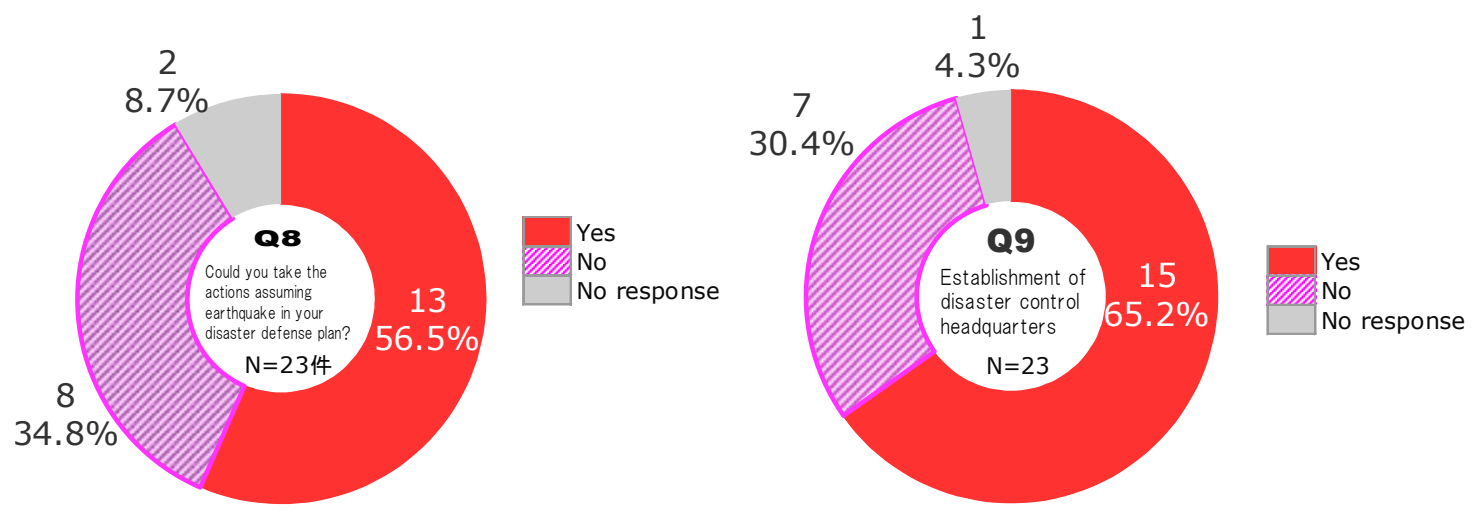

Fig.20 Actions by disaster defense plan

Fig.21 Formation of disaster control headquarters

(9) Information collection activity on the day of the 3.11 Earthquake 
The most common way of gathering information at the time of the Great East Japan Earthquake was "by TV" with 22 reported cases, followed by "by the Internet" with 19 cases and "informed by disaster control headquarters in other hubs, internal disaster control center, or building management company" with 9 reported cases. Also asked by an open-ended question of what information was provided then, the answers of which included "information on earthquake or transportation" and "operation status of building facilities". Many companies used the Internet and TV to collect information, and this was because the infrastructures were functioning in the Tokyo Metropolitan area. However, assuming that an earthquake occurs directly beneath the Metropolitan area, it is also necessary to consider preparing means to collect information even under commercial power outage.

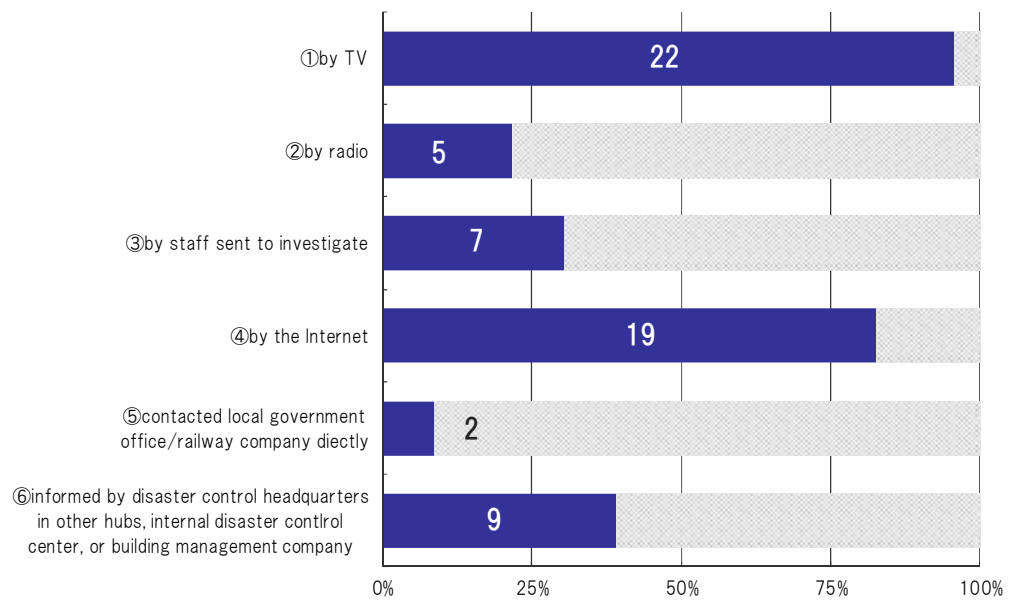

Fig.22 information gathering at tenants

\section{(10) Provision of information to employees}

The most common way to provide information to the employee in the office was "told around the office what was happening" with 14 tenants followed by "sent emails simultaneously" with 12 tenants and "posted information on internal systems" with 5 tenants (Fig.23). The detail of "other ways" was asked in an open-ended question, which received the answers including "on whiteboard" and "on in-house TV". For the employees out of office, 19 tenants "made a phone call", 16 "sent an email to each of them" and 4 "sent emails simultaneously" (Fig.24).

Also, an open-ended question which asked what information was provided to the employees both in and out of office received the answers including "status of public transportation" and "how to secure food supply".

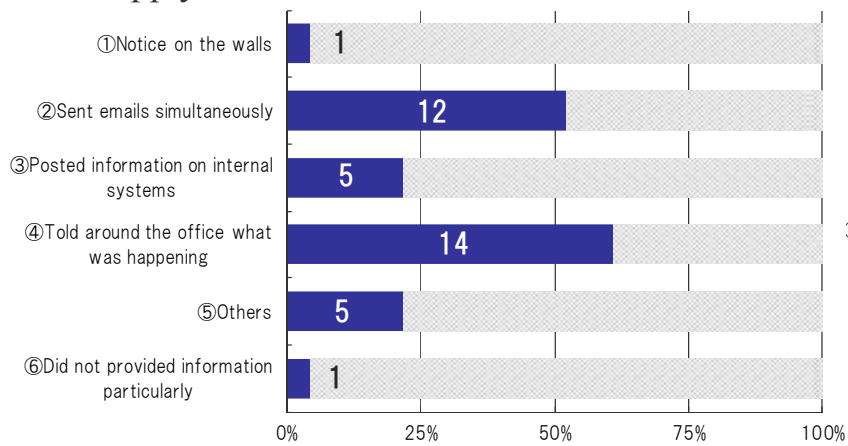

Fig.23 Provision of information to employees in the office

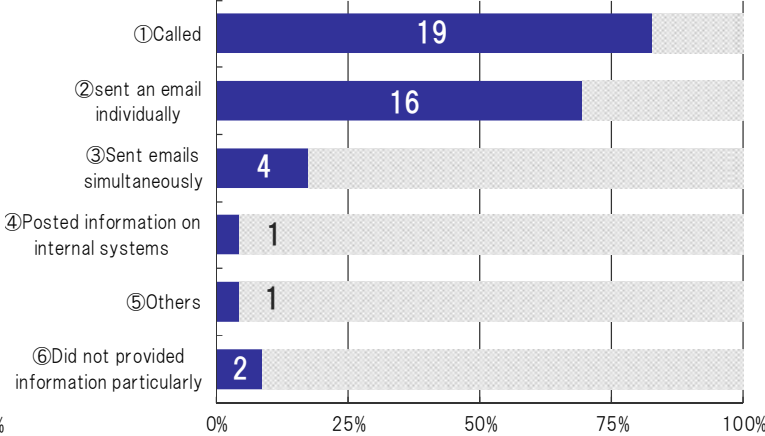

Fig.24 Provision of information to employees out of office

\section{(11) Past seismic countermeasures}

The most common earthquake countermeasures prior to the 3.11 Earthquake was "preparing stockpiles" 
with 18 tenants, followed by "fixing office furniture and automation equipment" with 16 tenants, "preparing manuals of initial responses in earthquake" with 14 tenants and "introduction of safety confirmation systems" with 13 tenants (Fig.25). Open-ended questions asking details of each option received the following answers.

The contents of drills answered were "processing safety confirmation systems", "confirmation of damage situation", "communication and evacuation" and "drills for business continuity at a backup hub".

Emergency supplies currently in stock included "food", "drinking water", "toilet" and "emergency packs". In addition, "helmets", "warm meals" and "blankets" were what they felt necessary to be stocked in the future.

Actions taken by the tenants that had introduced the 3.11 Earthquake early warning system on receipt of a warning were "in-building announcements", "security efforts such as wearing a helmet and going under a desk" and "staying temporarily in the building."

Furniture that had been fixed by the responding tenants before the 3.11 Earthquake included "cabinets", "book shelves", "servers", "lockers" and "large-size equipment."

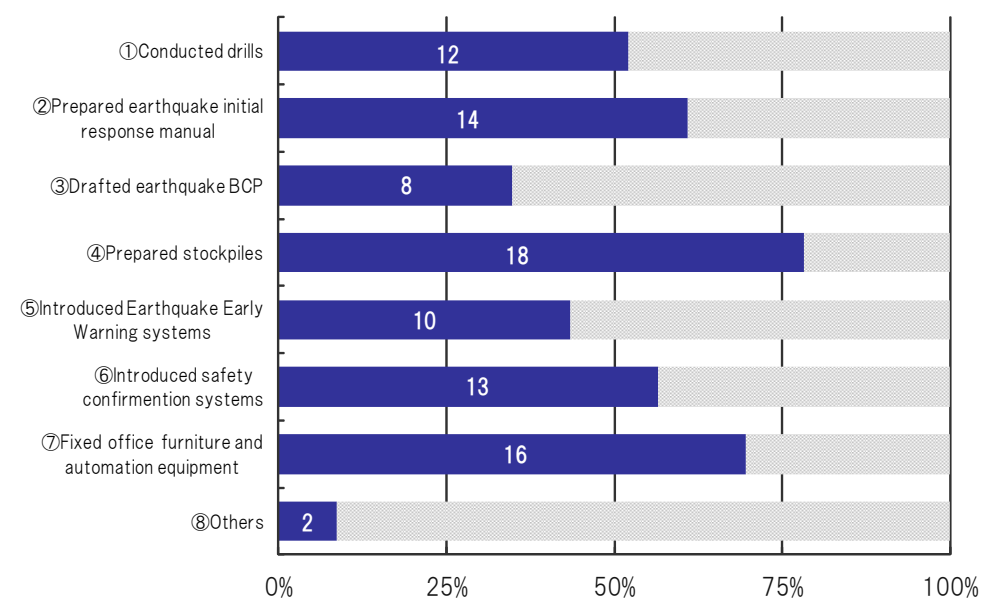

Fig.25 Past seismic countermeasures

\section{(12) Problems and reflection points}

Despite the fact that the tenants had taken various earthquake countermeasures as described above, many problems were found during the 3.11 Earthquake. Following table shows the problems or the reflection points they found, which were answered to the open-ended questions regarding the initial responses of the day.

Table 7 Problems and reflection points for the tenant companies regarding their handling during the

\subsection{Earthquake}

\section{(1) Stockpiles}

- The employees were not well informed of stockpile items and the storage locations. The number of helmets was not enough.

- Stockpiles for people unable to return home should be considered.

(2) Collection and provision of information

- Information needs to be simultaneously provided to all the employees.

- Provision of directions and information to the staffs who were working out of the office was inadequate.

- Handling of the people on a business trip had not been considered

(3) Anti-earthquake measures

- The shelves storing emergency equipment that are not fixed need to be checked and fixed.

(4) Handling of injured people

- There is a shortage of the staffs who are able to reach and treat injured people

(5) Preparation of manuals 
- There were no manuals or action guidelines to follow for the people who decided to stay in the building.

- There were no rules needed for an overnight stay in the office

- Roles of each staff were obviously either unclear or little understood

- The business continuity plans need to be reviewed.

(6) Disaster drills in place

- Disaster drills have been conducted but whether they are helpful at the time of an disaster is questionable.

(7) Safety confirmation

- Safety conformation was difficult without telephone or email.

- The safety confirmation system did not work as planned; some people did not receive the email, and the confirmation of safety of all the employees was not achieved.

\section{(13) Future effort}

An open-ended question was asked for the tenants to hear about their future effort based on the problems they found in the 3.11 Earthquake. Regarding disaster drills, they answered "repetitive execution of earthquake drills" and "practice of the registration to the safety confirmation system". The answers about manuals included "action guidelines for the people remaining in the building", "manuals for the employees on a business trip". Some additionally mentioned that they wanted "guidelines for the participation to regional disaster prevention activities" to be considered. Regarding stockpiles, they felt the necessity "to increase the variety" as well as "to thoroughly inform the people of the storage locations". Other efforts they found needed were "the introduction of satellite telephone to contact remote areas" and "knowledge of disaster message phone service".

\section{EFFORT FOR IMPROVING REGIONAL DISASTER PREVENTION ABILITY}

In order for a community to improve the ability to prevent disasters, both "self-help" effort and "mutual assistance" effort are required. While each business entity needs to help itself to improve the ability, community collaboration with other businesses in the same area is also necessary. This paper makes a preposition for the future improvement in light of the result of the questionnaire and based on the lessons learned from the 3.11 Earthquake. It should also be noted that in the Shinjuku West area, the impact of the 3.11 Earthquake to the lifeline utilities, for example large-scale blackouts, and the damage to the buildings themselves and the major facilities were limited.

\subsection{Effort by self-help approach}

\section{(1) Effort of management company}

Building management companies should minimize confusion of the tenants and the users of the building. For this, confirmation of what is happening in and around the building as well as appropriate provision of information to the people inside should be most prioritized. It is also desirable that the building accepts stranded people based on local circumstances and if only it has enough capacity.

(1) In-building collaboration to prepare for earthquake

This questionnaire revealed that the building management companies and the tenants conducted different activities including decision of evacuation. In general, the disaster control center of a building management company is run by several staffs and what could be done by the management company during a large-scale earthquake is quite limited. It is therefore necessary for them even in peacetime to collaboratively work with the tenants and relevant government offices on activities for the time of an earthquake. A cooperative relation is required to secure means of communication and provision of information and to clarify their respective roles and responsibilities in disaster countermeasures activities. 
Based on what happened in the area on the day of the 3.11 Earthquake, it would be necessary to form disaster control headquarters at the time of a disaster to cooperate with the tenants and the community. In the questionnaire, 4 buildings did not form headquarters during the Great East Japan Earthquake. It is also desirable to conduct earthquake drills in peacetime and check the viability of information sharing among the tenants and the community led by the disaster control headquarters of a building.

(3) Installation of seismography

This paper indicates that collaborative behaviors by building management companies and the tenants will be effective in the future, and in order for them to do so, it is important that the building management companies understand the extent of damage in the building. However, the disaster control center of a high-rise building is located either in the basement or on the ground floor in general, making it difficult to understand what is happening in the building as earthquake shock can largely vary by floor. Installation of seismographs, just like fire alarm systems for fire protection, will enable the disaster control center to centrally monitor how people behave on the mid to higher floors and the information obtained can be provided appropriately across the building.

(4) Measures for people unable to return home

At the occurrence of a large scale earthquake like the Great East Japan Earthquake, it is expected that a large number of people will be unable to go home. In order to minimize confusion in the community, it is desirable for each building in the area to provide appropriate information to stranded people and where possible, to accept people especially the elders or the injured who require assistance.

(5) Implementation of in-building seismic countermeasures

In the 3.11 Earthquake, various damages were found both inside and outside of buildings mainly in non-structural components or the elevators. It is important to implement fall prevention measures for equipment and furniture more thoroughly. In particular, elevators are considered to require retrofitting in accordance with the latest guidelines in 2009.

\section{(2) Effort of tenant}

In the Shinjuku West Gate area, respective sky-scrapers, during office hours of weekdays, hold a few thousand people. The tenants are expected to primarily focus on ensuring the safety of the staff, and they should make it a general rule to prevent the people from leaving the office in order to avoid confusion in the community unless a fire breaks out.

(1) Thoroughgoing seismic countermeasures in the office

Furniture and equipment in the office need to be thoroughly fixed to prevent injuries and to secure enough space for the people to safely stay in the office. It is also desirable to prepare people who are able to engage in first aid activities in case someone suffers minor or moderate injuries.

(2) Thoroughgoing stand-by in the office

In order to prevent confusion in the area shortly after a large-scale earthquake, it is necessary for each tenant company to make it a general rule to make the people stay in the office until the situation is confirmed. For a thoroughgoing stand-by in the office, in addition to stockpiles which will be described later, the effort to secure means to obtain information on the safety of family becomes important. Additionally, if the air conditioning does not work in an air-tight high-rise building, evacuation to outside should be assumed to occur depending on weather conditions.

(3) Review of stockpiles

To ensure people stay inside the office, even when utilities suffer epicentral earthquake damages, in addition to water and food, protection against cold as well as portable toilets are needed on the assumption that air conditioning or water and sewerage may be unavailable, which was suggested in existing reports such as Shinjuku survival book ${ }^{14)}$.While the Great East Japan Earthquake occurred in March, it is important secure water for the people suffering heat disorders assuming a similar earthquake 
occurs in summer.

\subsection{Effort by mutual assistance approach}

Public assistance is unlikely to be expected shortly after a large-scale earthquake, as the damage spread through a wide area. Self-help effort is therefore most important but additionally, beyond independent efforts by respective businesses, joint disaster prevention and mitigation effort made by various parties in the community based on the idea of mutual assistance is meaningful in order for the community to solve its common problems and to achieve a quick recovery as a whole. District-Wide Business Continuity Plan (DCP) is a concept of regional disaster prevention by a joint effort of businesses in a community that has been proposed in existing reports such as Nishikawa ${ }^{11}$.

Practical DCP approach has been taken in the Shinjuku West Gate Area, as has been reported by Kogakuin University ${ }^{12) 13)}$. For a further promotion of disaster prevention and mitigation activities, based on the lessons learned from the 3.11 Earthquake, the following efforts are proposed.

(1) Information sharing through community collaboration

During the Great East Japan Earthquake, information gathering across a wide area did not face a big problem as infrastructural damage was quite limited. However, if an epicentral earthquake causes a power outage, information gathering will become more difficult. An effort to share area specific information in the community is needed to understand what is happening there and to provide the information to stranded people. Prior to the 3.11 Earthquake, the Shinjuku West Gate area had formed the regional headquarters to collect, organize, and share local information. During the 3.11 Earthquake, however, no one gathered in the headquarters and the mechanism did not practically work. For a viable information sharing mechanism centered on regional headquarters, it should get set up by a minimum number of people. Also, it should establish an information sharing network (Fig.26) together with the disaster control centers of the buildings and the offices in the community to work cooperatively and share the above mentioned respective problems.

In the future, a permanent "regional disaster control center" run by the dedicated staff will need to be established. The center will engage in educational activities and conduct periodic drills for community disaster prevention at peacetime and have a mechanism to play a central role as regional headquarters in performing disaster control activities of community alliance in the event of an emergency. However, there are some legal issues yet to be solved to let the regional disaster control center lead the disaster control activities. A decision-making power needs to be transferred to the center, and the responsibility and indemnity in relation to the activities need to be considered.

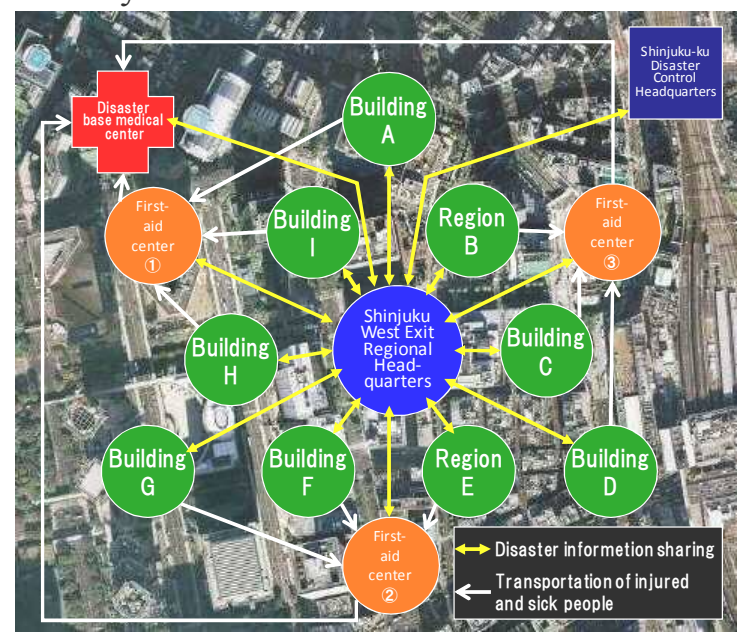

Fig.26 Image of community collaboration centered on the Shinjuku West Gate regional headquarters 
(2) Safety confirmation of building by community collaboration

It is indispensable to confirm the safety of the building to let the company employees stay for a long time and to accept people remaining in the neighborhood. The precise degree of damage in a building needs to be appraised by the specialists such as architects, who should be sourced within the community. The number of such specialists is often limited, and therefore the businesses in the area need to make an effort to send volunteers who support them.

(3) Establishment of the concept for behaviors on earthquake occurrence based on information sharing in community

This questionnaire found that the tenants decided in their sole discretion to evacuate despite the fact that the management companies had not instructed them to do so. Shortly after an earthquake in which there is no fire, if people start to evacuate immoderately, not only confusion is caused but also evacuees' safety could be risked. The above mentioned problem could have been avoided if information collected by the management companies had been appropriately provided to the tenants companies. In the future, it will be necessary to establish a system to share the safety information of the building across the tenants. Also, either by building or by area, each tenant is required to share the same concept of how to behave, which include evacuation, in an earthquake.

(4) Disaster drills by community collaboration

Continuous execution of earthquake drills through community collaboration is indispensable as they are the venue where the efforts for disaster prevention/mitigation through both self-effort and mutual assistance approaches are practiced and evaluated. Necessary knowledge of earthquake countermeasures needs to be shared and the businesses in the area should come together to continuously promote a system under which the activities related to the strategies of regional disaster prevention based on the result of drills are reviewed.

\section{CONCLUSION}

It was fortunate that the Great East Japan Earthquake did not cause severe damage to the Shinjuku West Gate area. It is expected that the lessons learned are fully utilized and the efforts to prepare for epicentral earthquakes is further advanced through the leadership of the Disaster Prevention Countermeasure Conference for Shinjuku Station Areas. Shinjuku New Urban Center, which has played a pivotal role in Japan's economic activities since 1970s, is now facing a big turning point. It aims to be a safe and secure but vigorously attractive city by upgrading earthquake prevention efforts of the Shinjuku West Gate area to a wider area management in the future through which various approaches of community collaboration are practiced.

\section{ACKNOWLEDGEMENT}

The questionnaire was conducted by the Disaster Prevention Countermeasure Conference for Shinjuku Station Areas West Gate Division. We would like to extend our gratitude to the businesses in the West Gate area who took their time to answer the questionnaire, to Shinjuku Fire Station which is the head office of West Gate Division, to Kogakuin University and to Shinjuku Ward crisis management section. 


\section{APPENDIX}

Table 8 Questionnaire for building management companies

\begin{tabular}{|c|c|c|}
\hline \multicolumn{2}{|l|}{ Questions } & Descriptions \\
\hline $\begin{array}{l}\text { Basic } \\
\text { information }\end{array}$ & 1. Building Outline & $\begin{array}{l}\text { - Building name, year of completion, company name, scale } \\
\text { (above grade/below grade), amount of total floor area, no. } \\
\text { of tenants, construction, vibration control mechanism, } \\
\text { building management (daytime/nighttime) }\end{array}$ \\
\hline \multirow{5}{*}{$\begin{array}{l}\text { Initial } \\
\text { responses in } \\
\text { the } 3.11 \\
\text { Earthquake }\end{array}$} & $\begin{array}{l}\text { 2. Damage found in the building on the } \\
\text { day of the } 3.11 \text { Earthquake }\end{array}$ & $\begin{array}{l}\text { (1) infrastructure } \\
\text { (2) elevators } \\
\text { (3) inside } \\
\text { (4) outer walls } \\
\text { (5) others }\end{array}$ \\
\hline & $\begin{array}{llll}\text { 3. Formation of Disaster Control } \\
\text { Headquarters }\end{array}$ & - When, where, what activities, decision making division \\
\hline & $\begin{array}{l}\text { 4. Actions taken on the occurrence of the } \\
\text { 3.11 Earthquake }\end{array}$ & $\begin{array}{l}\text { (1) Information gathering on the day } \\
\text { (2) Handling on the day (understanding of injured people } \\
\text { and damage, tenants' overnight stay, contents of internal } \\
\text { announcements) } \\
\text { (3) Handling from the following day onward } \\
\text { (4) Problems and reflection points regarding handling of the } \\
\text { 3.11 Earthquake }\end{array}$ \\
\hline & $\begin{array}{l}\text { 5. Behaviors and actions in the disaster } \\
\text { defense plan }\end{array}$ & - Items achieved according to plan and reason of failure \\
\hline & $\begin{array}{l}\text { 6. Decision of evacuation from the } \\
\text { building }\end{array}$ & $\begin{array}{l}\text { - Reason for not issuing an evacuation directive, timing and } \\
\text { place directed and the reasons }\end{array}$ \\
\hline \multirow{3}{*}{$\begin{array}{l}\text { Handling of } \\
\text { people unable } \\
\text { to return home }\end{array}$} & $\begin{array}{l}\text { 7. Provision of information to stranded } \\
\text { people in and around the building }\end{array}$ & $\begin{array}{l}\text { (1) Means to inform stranded people of situation } \\
\text { (2) Contents of info provided }\end{array}$ \\
\hline & 8. Acceptance of stranded commuters & $\begin{array}{l}\text { - Request from Tokyo Met. Gov., reply to the request, no. of } \\
\text { people accepted, impact of receiving people, material } \\
\text { assistance to the people }\end{array}$ \\
\hline & 9. Overnight stay in common areas & $\begin{array}{l}\text { (1) Did someone stay overnight in the common areas of your } \\
\text { building? } \\
\text { (2) For buildings with accommodation (hotel), were the } \\
\text { guest rooms offered? If so, no. of the rooms used and no. of } \\
\text { the people stayed }\end{array}$ \\
\hline \multirow{3}{*}{$\begin{array}{l}\text { company effort } \\
\text { and future } \\
\text { countermeasure }\end{array}$} & 10. Past seismic countermeasures & - Past seismic countermeasures \\
\hline & 11. Future effort & $\begin{array}{l}\text { - Review of future countermeasures (plan to start review, } \\
\text { structure/items to be reviewed, prospect of timing of } \\
\text { drawing a conclusion) }\end{array}$ \\
\hline & 12. Comments and others & $\begin{array}{l}\text { - Others: opinions, questions, items you think necessary to be } \\
\text { discussed by Council and jointly worked out by } \\
\text { community, requests to public administration }\end{array}$ \\
\hline
\end{tabular}

Table 9 Questionnaire for tenants

\begin{tabular}{|c|l|l|}
\hline \multicolumn{2}{|l|}{ Questions } & Descriptions \\
\hline $\begin{array}{c}\text { Basic } \\
\text { information }\end{array}$ & 1. Company outline & $\begin{array}{l}\text { - Company name, capital, total no. of employees, office name, } \\
\text { tenant floor, no. of enrollment, no. of people in the office on } \\
\text { the day (no. of visitor) }\end{array}$ \\
\hline \multirow{2}{*}{$\begin{array}{c}\text { Initial } \\
\text { responses in } \\
\text { the 3.11 } \\
\text { Earthquake }\end{array}$} & $\begin{array}{l}\text { 2. Damage found in the office } \\
\text { (2) inside } \\
(3) \text { other damage found }\end{array}$ \\
\cline { 2 - 3 } & $\begin{array}{l}\text { 3. Safety confirmation of the employees } \\
\text { employees }\end{array}$ & • When, what, target and completion date and time \\
\cline { 2 - 3 } 5. Decision of returning home & $\begin{array}{l}\text { - Reason for not issuing an evacuation directive, timing and } \\
\text { place directed and the reasons }\end{array}$ \\
\hline $\begin{array}{c}\text { Handling of } \\
\text { people unable } \\
\text { to return home }\end{array}$ & 6. Overnight stay in the office & - Policy and the reason \\
\hline
\end{tabular}




\begin{tabular}{|c|c|c|}
\hline \multicolumn{2}{|l|}{ Questions } & \multirow{2}{*}{$\begin{array}{l}\text { Descriptions } \\
\text { - Earthquake countermeasures taken prior to the } 3.11 \\
\text { Earthquake (contents of disaster drills, availability of } \\
\text { manuals, contents of stockpile, etc.) }\end{array}$} \\
\hline $\begin{array}{c}\text { Company } \\
\text { effort }\end{array}$ & 7. Past seismic countermeasures & \\
\hline \multirow{4}{*}{$\begin{array}{l}\text { Initial } \\
\text { responses in } \\
\text { the } 3.11 \\
\text { Earthquake }\end{array}$} & $\begin{array}{l}\text { 8. Behaviors and actions taken in the } \\
\text { context of disaster defense plan }\end{array}$ & Items achieved according to plan and reason of failure \\
\hline & $\begin{array}{l}\text { 9. Formation of Disaster Control } \\
\text { Headquarters }\end{array}$ & - When, where and what activities \\
\hline & 10. Information collection activity & - Provision of information on area around office \\
\hline & $\begin{array}{l}\text { 11. Means of provision of information to } \\
\text { the employees }\end{array}$ & $\begin{array}{l}\text { (1) Employees in the office } \\
\text { (2) Employees out of office } \\
\text { (3) Contents of info. Provided to employees in and out of } \\
\text { office }\end{array}$ \\
\hline \multirow{3}{*}{$\begin{array}{l}\text { company effort } \\
\text { and future } \\
\text { countermeasure }\end{array}$} & $\begin{array}{l}\text { 12. Problems and reflection points found } \\
\text { during the } 3.11 \text { Earthquake }\end{array}$ & $\begin{array}{l}\text { - Problems and reflection points found regarding past effort } \\
\text { and handling of your company during the 3.11 Earthquake }\end{array}$ \\
\hline & 13. Future effort & $\begin{array}{l}\text { - Review of future countermeasures (plan to start review, } \\
\text { structure/items to be reviewed, prospect of timing of } \\
\text { drawing a conclusion) }\end{array}$ \\
\hline & 14. Comments and others & $\begin{array}{l}\text { - Others: opinions, questions, items you think necessary to be } \\
\text { discussed by Council and jointly worked out by community, } \\
\text { requests to public administration }\end{array}$ \\
\hline
\end{tabular}

\section{REFERENCES}

1) Murakami, M. and Hisada, Y. : Study on the measure against victims unable to return home and the disaster medical system in the central business district around Shinjuku Station, Tokyo, $13^{\text {th }}$ Symposium of Japan Association for Earthquake Engineering, 2010, ROMBUNNO.OS5-SAT-PM(OS5)-6 (in Japanese).

2) Shindo, J., Murakami, M., Hiramoto, T., Masuzawa, Y., and Hisada, Y. : Study on Earthquake Disaster Mitigation by collaborating with local communities in Shinjuku Part2: Shinjuku-west gate Field Headquarters Training, Architectural Institute of Japan academic lecture digest (Kanto), F-1, 2011, pp.903-904 (in Japanese).

3) Kojima, T.: Disaster mitigation activities by cooperation with university and local community in Shinjuku subcenter, Japan, The Quaternary Research Vol.50 (5) pp259-264 (in Japanese).

4) Tokyo Fire Department : 2012 Report of Special Committee of safety measures for high rise apartment rooms against long period ground motion, 2012 (in Japanese).

5) Midorikawa, S., Miura, H., Hori, S., and Kashima T. : Questionnaire Survey on Effect of Shaking at Highrise Apartment in Tokyo during the 2011 off the Pacific Coast of Tohoku Earthquake, Institute of Social Safety Science No.28, 2011, pp.1-2 (in Japanese).

6) Hida, T. and Nagano, M., : Shaking and Damage of Super High-rise Residential Buildings during the 2011 Off the Pacific Coast of Tohoku Earthquake Based on Questionnaire Survey, Proceedings of the $8^{\text {th }}$ Annual Meeting of Japan Association for Earthquake Engineering, 2011, pp.34-35 (in Japanese).

7) Kubo, T., Hisada, Y., Aizawa, K., Ohmiya, K., and Koizumi, S. : Questionnaire Survey on Super high-rise buildings in the Shinjuku West gate area in the 2011 Great East Japan Earthquake Part 1, shaking at the Kogakuin Univeristy Shinjuku Campus building and a questionnaire for earthquake intensity survey, Proceedings of the $8^{\text {th }}$ Annual Meeting of Japan Association for Earthquake Engineering, 2011, pp36-37 (in Japanese).

8) Architectural Institute of Japan Research, Committee on Structures, Measures for Long Period Ground Motion Working Group : Reference materials for open research assembly of policies on measures for long period ground motion, 2011, (in Japanese). 
9) Council for the Alleviation of Subterranean Urban Earthquake Commuter Distress : Interim report (draft) of Council for the Alleviation of Subterranean Urban Earthquake Commuter Distress, 2012, (in Japanese).

10) Fire Equipment and Safety Center of Japan, Tokyo DSEM Association : Self-defensive fire-fighting operation center staff training textbook, 2009 (in Japanese).

11) Nishikawa, S. : Evolution of Japanese corporate disaster management to business continuity planning (BCP) and to District-wide BCP (DCP), $13^{\text {th }}$ Symposium of Japan Association for Earthquake Engineering, 2010, ROMBUNNO.OS5-SAT-PM(OS5)-1 (in Japanese).

12) Kogakuin University : 2011 Report on earthquake drills in the Shinjuku West Gate area, 2011, (in Japanese).

13) Kogakuin University : 2010 Report on Kogakuin University earthquake drills, 2010 (in Japanese).

14) Shinjuku City : Shinjuku Survival Book, 2009 (in Japanese).

(Original Japanese Paper Published: September, 2012)

(English Version Submitted: September, 3, 2014)

(English Version Accepted: October, 30, 2014) 